\title{
A new species of the feather mite genus Rhinozachvatkinia (Acari: Avenzoariidae) from Calonectris shearwaters (Procellariiformes: Procellariidae): integrating morphological descriptions with DNA barcode data
}

\author{
Laura M. Stefan ${ }^{1,2,4}$, Karen D. McCoy ${ }^{2}$ and Sergey Mironov ${ }^{3}$ \\ ${ }^{1}$ Institut de Recerca de la Biodiversitat and Departament de Biologia Animal, Universitat de Barcelona, Barcelona, Spain; \\ ${ }^{2}$ MIVEGEC Research Unit, 5290 CNRS-IRD-UM1-UM2, Centre IRD, Montpellier, France; \\ ${ }^{3}$ Zoological Institute, Russian Academy of Sciences, Saint Petersburg, Russia
}

\begin{abstract}
Rhinozachvatkinia calonectris sp. n., a new species of the feather mite genus Rhinozachvatkinia Mironov, 1989 (Avenzoariidae: Bonnetellinae), is described from two species of shearwaters in the North-East of the Atlantic Ocean, Calonectris edwardsii (Oustalet) (type host) and Calonectris borealis (Cory) (Procellariiformes: Procellariidae). We completed the morphological description of this new feather mite species with sequence data on the mitochondrial cytochrome $c$ oxidase subunit I gene fragment (COI). The full generic status of Rhinozachvatkinia, originally established as a subgenus of Zachvatkinia Dubinin, 1949, is formally fixed and its systematic relationships are briefly discussed.
\end{abstract}

Keywords: Bonnetellinae, ectoparasites, taxonomy, morphology, molecular study, new species, mites, birds, COI

Feather mites (Astigmata: Pterolichoidea and Analgoidea) are the most common ectosymbionts associated with birds and develop their entire life cycle on their hosts. The approximately 2500 species described to date have been reported from all recent avian orders (Gaud and Atyeo 1996, Proctor 2003, Mironov and Proctor 2008). The majority of known feather mite species live permanently on the surface of wing feathers, where they feed on uropygial gland secretions and detritus associated with the feather barbs (Blanco and Tella 2001, Galván et al. 2008).

In the present study, we describe a new species of the feather mite genus Rhinozachvatkinia Mironov, 1989 (Avenzoariidae: Bonnetellinae) found on two species of shearwaters, Calonectris borealis (Cory) and Calonectris edwardsii (Oustalet) (Procellariiformes: Procellariidae). To date, only three species of Rhinozachvatkinia have been described from three procellariiform hosts belonging to different families: Rhinozachvatkinia graciosa Mironov, 1989 from Pachyptila desolata (Gmelin) (Procellariidae), Rhinozachvatkinia pelecanoidi Mironov, 1989 from Pelecanoides georgicus (Murphy et Harper) (Pelecanoididae) and Rhinozachvatkinia zygoloba Mironov, 1989 from Oceanodroma leucorrhoa (Vieillot) (Hydrobatidae) (Mironov 1989a).
Feather mites of the genus Rhinozachvatkinia share their habitat on the wing feather of procellariiform birds with two closely related avenzoariid genera, Promegninia Gaud et Atyeo, 1967 and Zachvatkinia Dubinin, 1949. The genus Promegninia is monotypic and known only from albatrosses (Procellariiformes: Diomedeidae) (Gaud and Atyeo 1967). The genus Zachvatkinia currently includes 15 species, of which five are known from procellariiforms of the families Diomedeidae, Procellariidae and Hydrobatidae, whereas remaining species are associated with gulls, terns and crab plovers (Charadriiformes: Laridae and Dromadidae) (Mironov 1989b, 1991a,b, 1992, Mironov and Stefan 2013, Negm et al. 2013). These three mite genera constitute the Zachvatkinia generic group within the subfamily Bonnetellinae - see Mironov and Dabert (1999).

It is necessary to note that Rhinozachvatkinia was originally established as a subgenus of Zachvatkinia by Mironov (1989a). Later, Mironov and Dabert (1999) carried out a phylogenetic analysis of Avenzoariidae and showed that Rhinozachvatkinia is much closer to Promegninia than to Zachvatkinia sensu stricto. Although these authors treated Rhinozachvatkinia as a genus in their work, they did not formally declare its full generic status. Therefore, we formally fix its status as a full genus in the present paper. 


\section{MATERIALS AND METHODS}

The material used in the present study was collected by Jacob González-Solís, Elena Gómez-Díaz and Teresa Militão from 2003 to 2008 from living birds breeding on the Cape Verde and Azores Archipelagos using the dust-ruffling method (for C. edwardsii; see Walther and Clayton 1997) or direct sampling of barbs from primary feathers (for $C$. borealis). Bird captures and mite sampling were carried out under permissions from the corresponding Governments authorities of Portugal and Cape Verde. All animals were handled in accordance with good animal care practices as defined by the current European legislation.

Collected material was preserved in vials with absolute ethanol. For morphological identifications, feather mites were cleared in lactic acid for $24 \mathrm{~h}$ and mounted on microscope slides in PVA medium (BioQuip Products, Rancho Dominguez, California). The new species description follows the standards used for avenzoariid mites (Atyeo and Gaud 1981, Mironov 1989b, Mironov and Dabert 1997). General morphological terms and leg chaetotaxy follow Gaud and Atyeo (1996), idiosomal chaetotaxy also follows these authors with corrections proposed by Norton (1998). All measurements are in micrometres $(\mu \mathrm{m})$. Drawings were made using a Leica DM 5000B light microscope with DIC illumination and camera lucida.

Prior to mounting on slides, six individual mites were subjected to DNA extraction using the nondestructive method described by Dabert et al. (2008). A 609-bp fragment of the COI gene was amplified using the primers bcdF05 (5'-TTTTCTACHAAYCATAAAGATATTGC-3') and bcdR04 (5'-TATAAACYTCDGGATGNCCAAAAAA-3') (Dabert et al. 2008). Polymerase chain reactions (PCRs) were carried out in a total volume of $25 \mu$ containing $2 \mu 110 \times$ reaction buffer with $\mathrm{MgCl}_{2}(15 \mathrm{mM})$ (Roche Diagnostics, Meylan, France), $1.5 \mathrm{mM}$ $\mathrm{MgCl}_{2}, 0.15 \mathrm{mM}$ of each dNTP, $0.4 \mu \mathrm{M}$ of each primer, $1.25 \mathrm{U}$ Taq DNA polymerase (Roche Diagnostics) and $3 \mu 1$ of DNA template. Amplification conditions consisted of an initial step of $5 \mathrm{~min}$ at $95^{\circ} \mathrm{C}$, followed by 35 cycles of $30 \mathrm{sec}$ at $95^{\circ} \mathrm{C}, 1 \mathrm{~min}$ $30 \mathrm{sec}$ at $50^{\circ} \mathrm{C}, 1 \mathrm{~min}$ at $72^{\circ} \mathrm{C}$, with a final step of $5 \mathrm{~min}$ at $72^{\circ} \mathrm{C}$. PCR products were separated by electrophoresis in $2 \%$ agarose gel and visualized under UV light. Samples containing visible bands were sent for sequencing to Beckman Coulter Genomics (France; GenBank Accession nos. KF111269-KF111274). Bioedit version 7.0.5.3 (Hall 1999) was used to assemble, edit and align sequences and all variable sites were confirmed by visual inspections of the chromatograms. Pairwise distances between sequences were computed with MEGA 4 (Tamura et al. 2007) using K2P distance model (Kimura 1980).

The taxonomic system and scientific names of birds follow Clements et al. (2012) and Sangster et al. (2012). Type and additional materials are deposited in the Zoological Institute of the Russian Academy of Sciences, Saint Petersburg, Russia (ZISP).

\section{RESULTS}

Family Avenzoariidae Oudemans, 1905

Subfamily Bonnetellinae Atyeo et Gaud, 1981

Genus Rhinozachvatkinia Mironov, 1989 stat. n.

As it was noticed above, the genus Rhinozachvatkinia was originally established as a subgenus of the genus $Z a$ - chvatkinia by Mironov (1989a). Later on, Mironov and Dabert (1999) proved that this taxon is phylogenetically closer to the genus Promegninia than to Zachvatkinia in a strict sense, but did not formally fix its full generic status.

Rhinozachvatkinia is clearly distinguished from the genus Zachvatkinia by the following set of characters: in both sexes, the subcapitulum is elongated and its distal part is noticeably narrowed (more expressed in females than in males), genual setae $m G \mathrm{I}$ are narrow lanceolate or spiculiform; in males, the lateral membranes of opisthosomal lobes are absent, the anterior ends of coxal fields IV are widely separated from each other, distance between them is equal to or wider than the genital arch; in females, the anterior margin of hysteronotal shield is distinct (Mironov 1989a,b). The two former characters also differentiate this genus from Promegninia. Within the Zachvatkinia generic group, the genera Promegninia and Rhinozachvatkinia could be referred to as small-sized representatives of this grouping; the idiosoma lengths of these mites do not exceed $450 \mu \mathrm{m}$ in males and $400 \mu \mathrm{m}$ in females, whereas in Zachvatkinia these lengths are over $600 \mu \mathrm{m}$ and $450 \mu \mathrm{m}$, respectively.

Type species: Zachvatkinia (Rhinozachvatkinia) graciosa Mironov, 1989 by original designation.

Other s pecies: Rhinozachvatkinia pelecanoidi Mironov, 1989, R. zygoloba Mironov, 1989 and one species described below.

Rhinozachvatkinia calonectris sp. n.

Figs. 1-4

Male (Figs. 1, 3, 4A,B) (holotype, measurements for one paratype in parentheses). Length of idiosoma from anterior end to end of opisthosomal lobes 440 (420), greatest width at level of humeral shields 210 (185). Subcapitulum moderately narrowed in anterior part, lateral margins with small tooth-like extensions, length including palps 62 (63), greatest width 46 (48), width at bases of palps 29 (32) (Fig. 4A). Chelicerae slightly narrowed in anterior part, 65 (63) long.

Prodorsal shield: pear-shaped, strongly narrowed in anterior part, without median ridges, with pair of ovate desclerotized patches, posterior margin convex, posterolateral margins rounded or with short angular extension, not encompassing bases of setae se, length along midline 95 (93), greatest width 63 (63) (Fig. 1A). Setae vi paired. Setae si situated on lateral margins of prodorsal shield, setae se situated on small circular plates near prodorsal shield, distance between setae se 80 (80). Length of hysterosoma from level of sejugal furrow to lobar apices 315 (300). Setae $c 3$ narrowly lanceolate, 15 (15) long.

Hysteronotal shield: anterior margin sinuous with noticeable concavities lateral to setae $c l$, anterior angles acute and almost touching humeral shields, greatest length from anterior margin to level of setae $h 3275$ (270), width at anterior margin 125 (125). Opisthosomal 

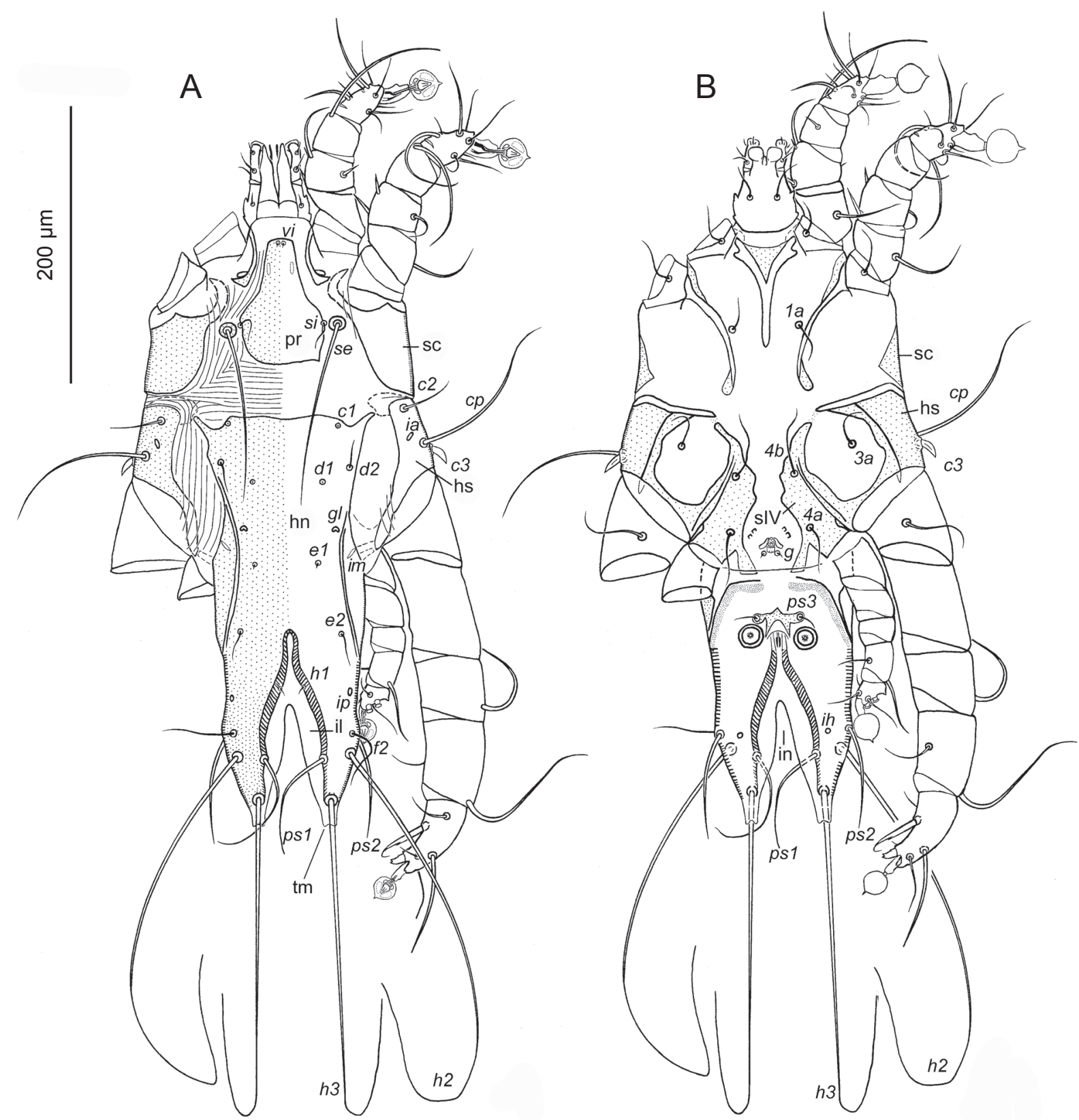

Fig. 1. Rhinozachvatkinia calonectris sp. n. from Calonectris edwardsii; male. A - dorsal view; $\mathbf{B}$ - ventral view. Abbreviations: ia, im, ip and ih-cupules; hn - hysteronotal shield; hs - humeral shield; il - interlobar membrane; in - incision in interlobar membrane; $\mathrm{pr}$ - prodorsal shield; sc - scapular shield; sIV - sclerotized area of coxal fields IV; tm - terminal membrane.

lobes long, strongly narrowed apically, well separated from each other. Terminal cleft between lobes deep and relatively narrow, extending to level of setae $e 2$, length including supranal concavity 138 (140), greatest width 40 (35). Inner margins of opisthosomal lobes without ledge, outer margins of lobes slightly convex, apical part posterior to bases of setae $h 3$ represented by narrow bidentate membranes (Fig. 1A). Lateral membranes not developed.

Interlobar membrane around two times narrower than lobe width at level of setae $p s 2$, gradually narrowing to bases of setae $h 3$. Incision in interlobar membrane not extending to level of setae $h l$, length of incision from ante- rior end to level of lobar apices 88 (90). Distance between dorsal setae $c 2: d 245$ (33), $d 2: e 2118$ (120), e2 $: h 288$ (85), h2: h3 30 (33), ps1 : h3 28 (30), d1 : d1 43 (35), el : el 40 (45), h2: h2 83 (80), h3:h3 53 (50). Setae ps 185 (75) long, around two times longer than $f 2$, extending beyond lobar apices.

Sternum about half as long as total length of epimerites I. Coxal fields III almost closed. Sclerotized areas of coxal fields IV widely separated from each other and anterior to genital apparatus (Fig. 1B). Setae $3 a$ situated anterior to level of setae $4 b$. Genital apparatus small, length 8 (7), width 15 (14), branches of genital arch short. Genital 


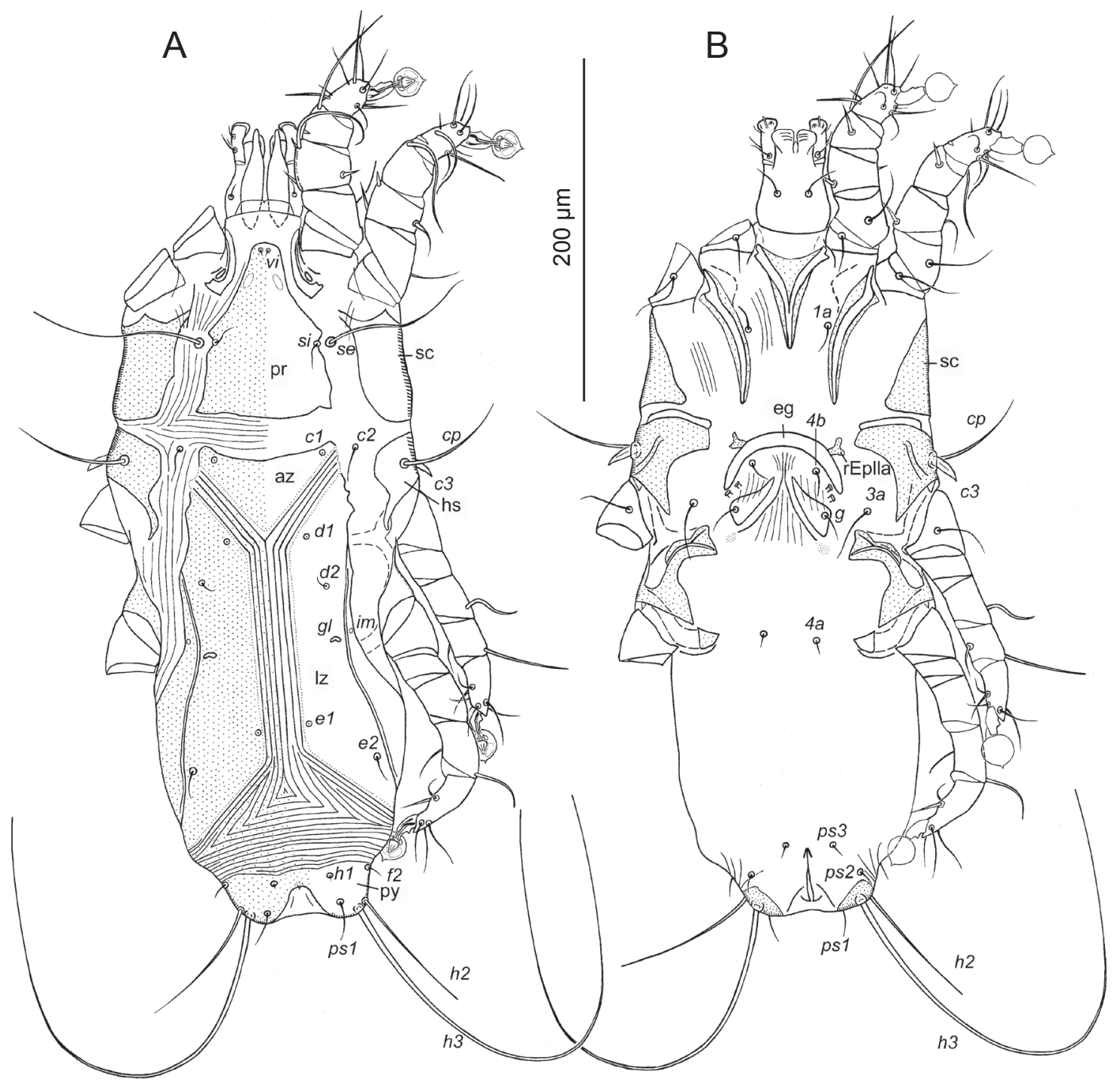

Fig. 2. Rhinozachvatkinia calonectris sp. n. from Calonectris edwardsii; female. A - dorsal view; B - ventral view. Abbreviation: $\mathrm{az}$ - anterior sclerotized zone of hysteronotal shield; eg - epigynum; hs - humeral shield; im - cupules; lz - lateral sclerotized zone of hysteronotal shield; pr - prodorsal shield; py - pygidial shield; rEpIIa - rudimentary sclerite of epimerites IIa; sc - scapular shield.

shields absent, setae $g$ situated on striated tegument immediately posterior to genital arch. Adanal shields fused each other forming star-like structure, its lateral branches bear setae ps3 (Fig. 4B). Diameter of adanal suckers 16 (17). Adanal apodemes narrow, poorly sclerotized. Distance between setae: $4 b: 4 b 48$ (30), $g: g 10$ (10), $4 a: g$ 18 (13), $g$ : ps3 45 (48), ps3 : ps3 30 (28).

Tarsi I, II with scarcely distinct apical spine-like processes (Fig. 3A,B). Setae $m G$ on genu I narrow spineshaped, on genu II filiform. Setae $c G$ of genua I, II narrow spine-like. Tarsus III 60 (62) long (Fig. 3C). Tarsus IV with one dorso-basal spine (Fig. 3D).

Female (Figs. 2, 4C-E) (range for two paratypes). Length of idiosoma 410-445, width 175-190. Gnathosoma shaped as in male, lateral margins without tooth-like extensions, length of subcapitulum including palps 69-
72, greatest width 49-51, width at bases of palps 37-39 (Fig. 4D). Palps not enlarged basally. Chelicerae slightly narrowed in anterior part, 72-75 long.

Prodorsal shield: strongly narrowed in anterior part, posterior part roughly rectangular; length along median line 100-113, greatest width 75-85 (Fig. 2A). Setae vi paired. Setae $s i$ situated on lateral margins of prodorsal shield, setae se situated on striated tegument near lateral margins of shield, distance between setae se 80-85. Length of hysterosoma from sejugal furrow to posterior margin of opisthosoma 295-305. Setae c3 narrowly lanceolate, 13-15 long.

Hysteronotal shield: with three dotted parts separated from each other by striated areas, anterior zone and a pair of lateral zones; posterior margin of hysteronotal shield medially indistinct (Fig. 2A). Anterior zone triangular in 


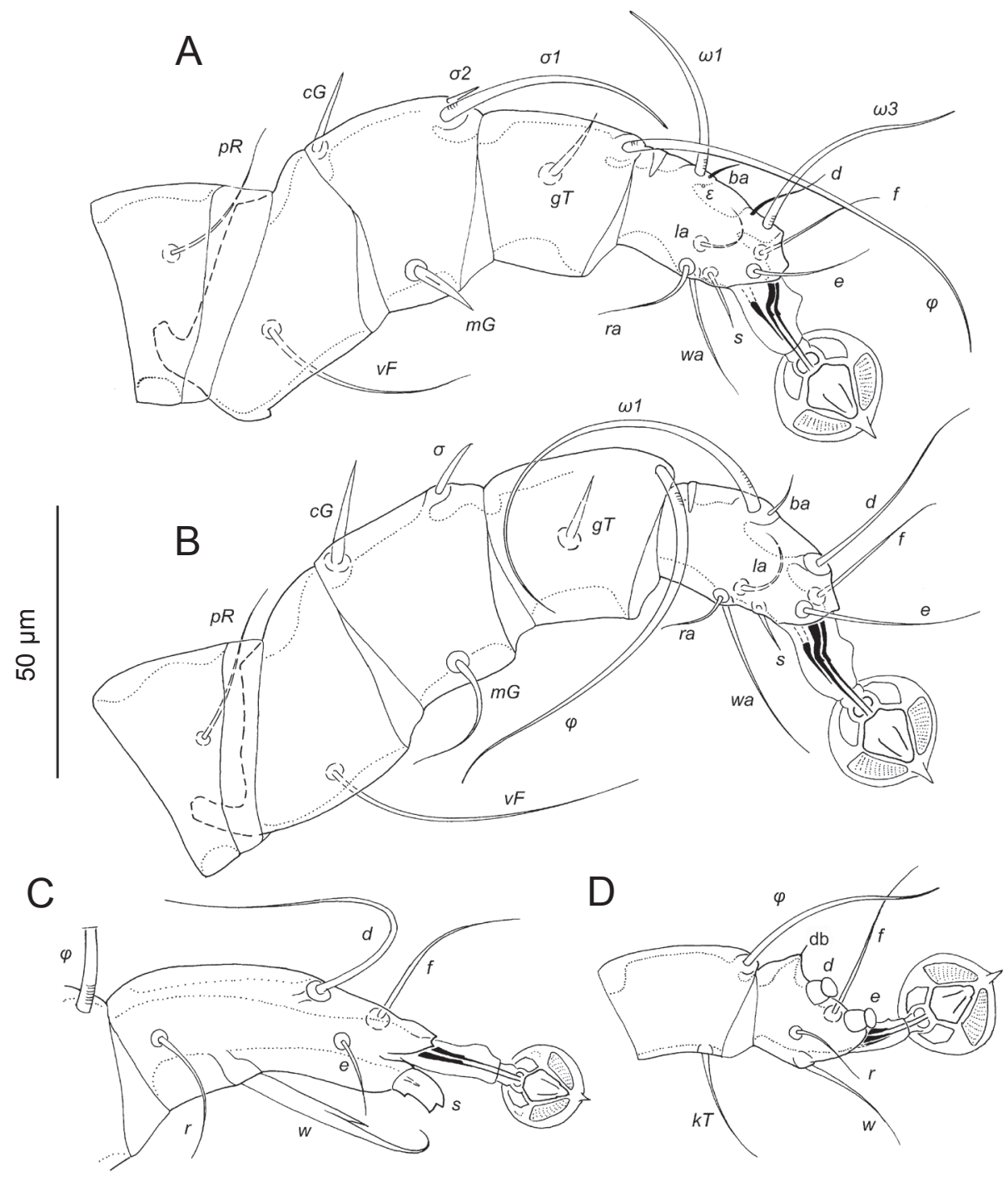

Fig. 3. Rhinozachvatkinia calonectris sp. n. from Calonectris edwardsii; legs of male. A - leg I; B - leg II; C - tarsus III; D - tibia and tarsus IV. Abbreviation: db - dorso-basal spine of tarsus IV.

shape, small, and bear setae $c 1$. Lateral zones bear setae $d 1, d 2, e 1, e 2$ and hysteronotal gland opening $g l$. Greatest length of hysteronotal shield (from anterior margin to posterior ends of lateral dotted zones) 238-250, width at anterior margin 85-90, width at posterior margin 120-125. Distance between dorsal setae $c 2: d 275-85, d 2: e 2110$, $e 2: h 3$ 85-88,h3:h3 60-68,dl:d1 45-50, el :el 28-30.

Pygidial shield 28-33 long, 85-90 wide. Epimerites I fused into Y, sternum about one third of total length of epimerites, bases of epimerites not thickened. Epigynum semicircular, thick, extending to level of anterior genital papillae (Fig. 2B), length 38-43, width 60-75. Rudimentary sclerites rEpIIa small and fused with epigynum. Setae $g$ situated at level of setae $3 a$ or slightly posterior.

Legs I, II as in male. Tarsi III, IV with small apical spine-like extension (Fig. 4C,E). Leg IV not extending to posterior end of the body.

Type host: Cape Verde shearwater Calonectris edwardsii
(Oustalet) (Procellariiformes, Procellariidae).

Type 1 ocality: Cape Verde, Boa Vista Island, Curral Velho Islet.

Date of collection: 12 July 2006, collected by Jacob González-Solís.

Type materia 1: Male holotype; one male and two female paratypes.

Deposition of material: Male holotype (ZISP 50211), one male (ZISP 5022) and two female paratypes (ZISP 5021-2, 5023).

Additional material: one male (ZISP 5024) from C. edwardsii, Cape Verde, Raso Island, 21 March 2008, collected by Teresa Militão; one female (ZISP 5025) from C. edwardsii, Cape Verde, Boa Vista Island, Curral Velho Islet, 8 July 2007, collected by Jacob González-Solís; one male and one female (ZISP 5026-1, 5026-2) from Cory's shearwater Calonectris borealis (Cory), Portugal, Azores Archipelago, Graciosa Island, Praia, 9 August 2003, collected by Jacob González-Solís; one male (ZISP 5027) from 

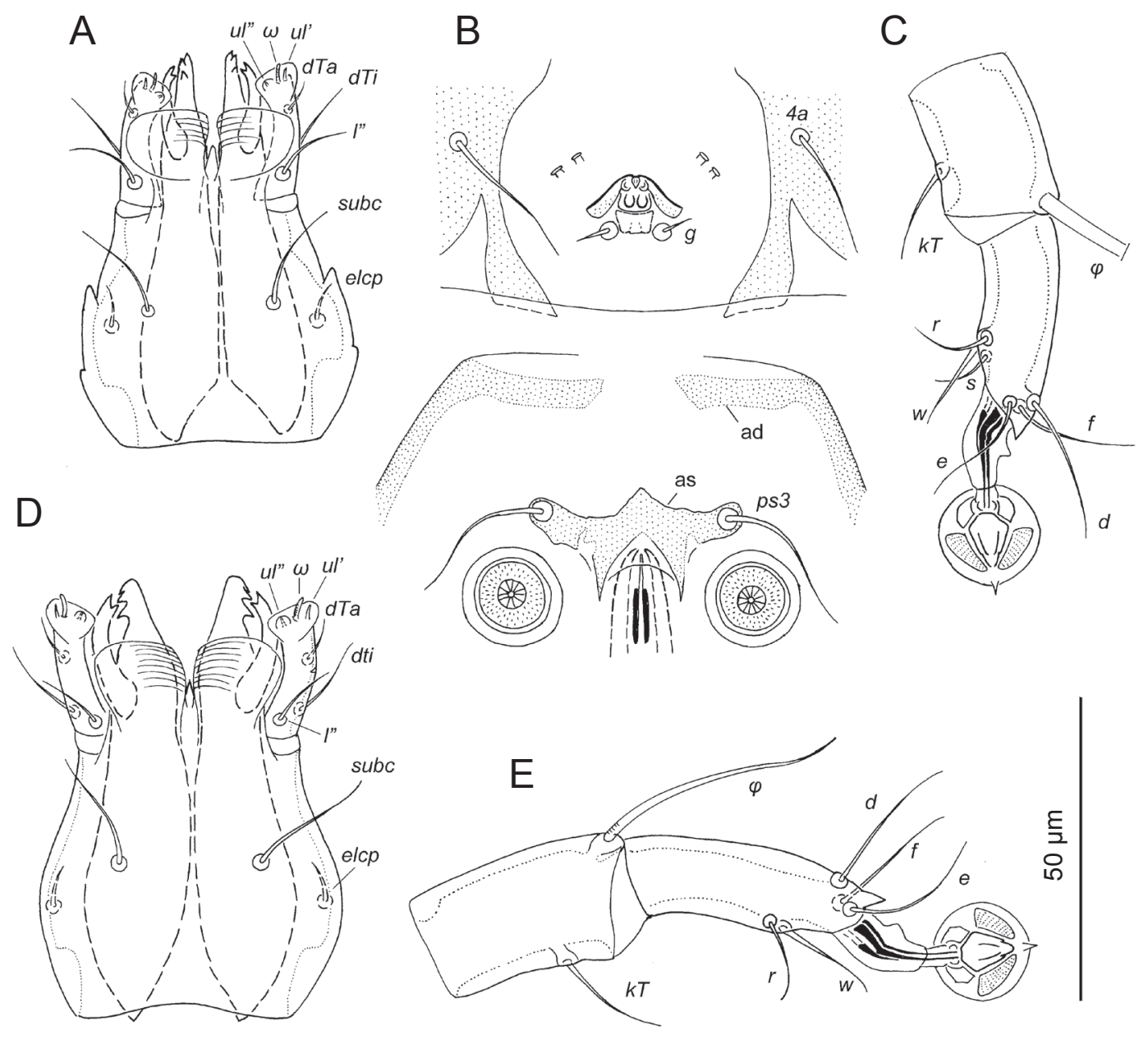

Fig. 4. Rhinozachvatkinia calonectris sp. n. from Calonectris edwardsii; details. A - gnathosoma of male, ventral view; $\mathbf{B}$ - genital and anal areas of male; $\mathbf{C}$ - tibia and tarsus III of female; D - gnathosoma of female, ventral view; $\mathbf{E}$ - tibia and tarsus IV of female. Abbreviations: ad - adanal apodeme; as - adanal shield.

C. borealis, Portugal, Azores Archipelago, Santa Maria Island, Vila, 9 June 2003, collected by Elena Gómez-Díaz; one male and one female (ZISP 5028-1, 5028-2) from C. borealis, Portugal, Azores Archipelago, Flores Island, Faja Lopo Vaz, 16 August 2003, collected by Jacob González-Solís; one male (ZISP 5029) from C. borealis, Portugal, Azores Archipelago, Corvo Island, Pesqueiros, 20 August 2003, collected by Elena Gómez-Díaz.

Etymology: The specific epithet is taken from the generic name of the type host and is a noun in apposition.

Differential diagnosis: Among three previously described species, Rhinozachvatkinia calonectris sp. n. is most similar to $R$. graciosa Mironov, 1989 described from Pachyptila desolata from Georgia Island (Mironov 1989) by having long and well separated opisthosomal lobes and star-shaped adanal shield in males.

The new species differs from $R$. graciosa by the following features: in both sexes, scapular setae se are situated off the prodorsal shield and subhumeral setae $c 3$ are lanceolate; in males, the terminal membranes are bidentate, setae $4 b$ are situated posterior to the level of setae $3 a$, and the adanal apodemes are narrow L-shaped; in females, the hysteronotal shield is separated by striated areas into three dotted zones (the anterior zone and a pair of lateral ones), and the rudimentary sclerites rEpIIa are small and fused to the epigynum.

In both sexes of $R$. graciosa, scapular setae se are situated on the prodorsal shield, and subhumeral setae $c 3$ are spiculiform; in males, the terminal membranes are acute apically, setae $4 b$ are situated anterior to the level of setae $3 a$, and the adanal apodemes are teardrop-shaped; in females, the hysteronotal shield has two lateral dotted parts, and the rudimentary sclerites rEpIIa are represented by a pair of transverse sclerites distinctly separated from the epigynum.

DNA barcode. We sequenced a 609-pb fragment of the mitochondrial cytochrome $c$ oxidase subunit I (COI) gene for one male paratype (Acc. No. KF111273, ZISP 5022), four males (Acc. No. KF111274, ZISP 5024; Acc. No. KF111270, ZISP 5026-1; Acc. No. KF111269, ZISP 5027; Acc. No. KF111272, ZISP 5029) and one female 
(Acc. No. KF111271, ZISP 5028-2) from additional material collected as described above. The average genetic distance (K2P) among the $R$. calonectris COI sequences was $1.2 \%$ (SE 0.3 ). The majority of nucleotide substitutions were synonymous and only two amino acid changes were detected (substitution of valine with isoleucine at positions 124 and 157).

Acknowledgements. The authors wish to thank Jacob GonzálezSolís, Elena Gómez-Díaz, Raül Ramos and Teresa Militão (Universidad de Barcelona, Spain), Veronica Neves (Scottish Natural Heritage, Scotland), Samir Martins (Association for the Conservation of the Environment and Sustainable Development, Cape
Verde) and Valérie Noël (CNRS, France) for sample collection and molecular assistance. Permits to capture and examine live procellariiform birds were issued by Secretaria Regional do Ambiente da Região Autónoma dos Açores, Direcção Geral do Ambiente and the Instituto Nacional de Investigação e Desenvolvimento Agrário from Cape Verde. The present investigation was performed during the postgraduate project of LS supported by the University of Barcelona. Financial support was provided by CGL2006-01315/BOS and CGL2009-11278/BOS from the Ministerio de Ciencia e Innovación (Spain) and Fondos FEDER for LS, by French ANR project EVEMATA (11-BSV7-003) and the CNRS, France for KM and by the Russian Foundation for Basic Research (grant No. 13-04-00608a) for SM.

\section{REFERENCES}

Atyeo W.T., Gaud J. 1981: The subfamilies of the Avenzoariidae (Acari: Analgoidea). J. Med. Entomol. 18: 341-344.

Blanco G., Tella J.L. 2001: Feather mites on birds: costs of parasitism or conditional outcomes? J. Avian Biol. 32: 271-274.

Clements J.F., Schulenberg T.S., Iliff M.J., Sullivan B.L., Wood C.L., Roberson D. 2012: The Clements Checklist of Birds of the World: Version 6.7. World Wide Web electronic publication, www.birds.cornell.edu/clementschecklist/downloadable-clements-checklist, 12/2012.

Dabert J., Ehrnsberger R., Dabert M. 2008: Glaucalges tytonis sp. n. (Analgoidea, Xolalgidae) from the barn owl Tyto alba (Strigiformes, Tytonidae): compiling morphology with DNA barcode data for taxon descriptions in mites (Acari). Zootaxa 1719: 41-52.

Galván I., Barba E., Piculo R., Cantó J.L., Cortés V., Monrós J.S., Atiénzar F., Рвосtor H. 2008: Feather mites and birds: an interaction mediated by uropygial gland size? J. Evol. Biol. 21: 133-144.

Gaud J., Atyeo W.T. 1967: Cinq genres nouveaux de la famille des Analgidae Trouessart \& Mégnin. Acarologia 9: 435-446.

Gaud J., Atyeo W.T. 1996: Feather mites of the World (Acarina, Astigmata): the supraspecific taxa. Ann. Mus. Roy. Afr. Centr., Sci. Zool. 277: 1-193 (Part I, text), 1-436 (Part II, illustrations).

HaLl T.A. 1999: BioEdit: a user-friendly biological sequence alignment editor and analysis program for Windows 95/98/NT. Nucl. Acids. Symp. Ser. 41: 95-98.

KimURA M. 1980: A simple method for estimating evolutionary rate of base substitutions through comparative studies of nucleotide sequences. J. Mol. Evol. 16: 111-120.

Mironov S.V. 1989a: A new subgenus and three new species of the feather mite genus Zachvatkinia from Procellariiformes. Parazitologiya 23: 309-319. (In Russian, with English summary).

Mironov S.V. 1989b: A brief review of the feather mites of the genus Zachvatkinia in the USSR (Analgoidea, Avenzoariidae). Parazitol. Sb. 36: 91-115. (In Russian, with English summary).

Mironov S.V. 1991a: [Two new feather mite species of superfamily Analgoidea from Antarctic birds.] Informatsionnyi Byulleten Sovetskoi Antarkticheskoi Ekspeditsii 116: 69-75. (In Russian.)

Mironov S.V. 1991b: The feather mites of the family Avenzoariidae, their classification and peculiarities of their host-distribu- tions. In: F. Dusbábek and V. Bukva (Eds.), Modern Acarology. Vol. 2. Academia, Prague and SPB Academia Publishing bv., The Hague, pp. 281-296.

Mironov S.V. 1992: Two new species of feather mites of the genus Zachvatkinia (Analgoidea: Avenzoariidae) from the crab plover. Parazitologiya 26: 497-505. (In Russian, with English summary.)

Mironov S.V., Dabert J. 1997: A systematic review of the feather mite genus Bychovskiata Dubinin (Analgoidea: Avenzoariidae) with the description of 11 new species. Mitt. Hamburg Zool. Mus. Inst. 94: 91-123.

Mironov S.V., Dabert J. 1999: Phylogeny and co-speciation in feather mites of the subfamily Avenzoariinae (Analgoidea: Avenzoariidae). Exp. Appl. Acarol. 23: 525-529.

Mironov S.V., Proctor H.C. 2008: The probable association of feather mites of the genus Ingrassia Oudemans, 1905 (Analgoidea: Xolalgidae) with the blue penguin Eudyptula minor (Aves: Sphenisciformes) in Australia. J. Parasitol. 94: 1243-1248.

Mironov S. V., Stefan L. M. 2013: Redescription of the feathermite species, Zachvatkinia puffini (Buchholz, 1869) (Acariformes: Avenzoariidae), from its type host, the Grey Petrel Procellaria cinerea Acarina 21: 27-37.

Negm M.W., Nasser M. G. E.-D., Alatawi F.J., Al Ahmad A.M., SHORBAK M. 2013: Feather mites of the genus Zachvatkinia Dubinin, 1949 (Astigmata: Analgoidea: Avenzoariidae) from Saudi Arabia: A new species and two new records. Zootaxa 3710: 61-71.

NORTON R. 1998: Morphological evidence for the evolutionary origin of Astigmata (Acari: Acariformes). Exp. Appl. Acarol. 22: 559-594.

Proctor H.C. 2003: Feather mites (Acari: Astigmata): ecology, behavior and evolution. Annu. Rev. Entomol. 48: 185-209.

Sangster G., Collinson J.M., Crochet P.-A., Knox A.G., ParKin D.T., Votier S.C. 2012: Taxonomic recommendations for British birds: eighth report. Ibis 154: 874-883.

Tamura K., Dudley J., Nei M., Kumar S. 2007: MEGA4: Molecular Evolutionary Genetics Analysis (MEGA) software version 4.0. Mol. Biol. Evol. 24: 1596-1599.

Walther B.A., Clayton D.H. 1997: Dust-ruffling: a simple method for quantifying ectoparasite loads of live birds. J. Field Ornithol. 68: 509-518.

Accepted 9 July 2013 